OPEN ACCESS

Edited by:

Marco Sarà

San Raffaele Cassino, Italy

Reviewed by:

Raffaele Palmirotta,

Università degli studi di Bari Aldo

Moro, Italy

Sergio Bagnato,

Fondazione Istituto G. Giglio di

Cefalu, Italy

*Correspondence:

Sung Hoon Kim

kimrehab@yonsei.ac.kr

Sung-Rae Cho

srcho918@yuhs.ac

tThese authors have contributed equally to this work.

Specialty section:

This article was submitted

to Neurotrauma,

a section of the journal

Frontiers in Neurology

Received: 30 November 2017

Accepted: 18 January 2018

Published: 13 February 2018

Citation:

Baek A, Kim JH, Pyo S, Jung J-H, Park EJ, Kim SH and Cho S-R (2018)

The Differential Effects of

Repetitive Magnetic Stimulation

in an In Vitro Neuronal Model of

Ischemia/Reperfusion Injury.

Front. Neurol. 9:50.

doi: 10.3389/fneur.2018.00050

\section{The Differential Effects of Repetitive Magnetic Stimulation in an In Vitro Neuronal Model of Ischemia/Reperfusion Injury}

\author{
Ahreum Baek ${ }^{1,2 t}$, Ji Hyun Kim ${ }^{1 \dagger}$, Soonil Pyo ${ }^{2,3}$, Joon-Ho Jung ${ }^{4}$, Eun Jee Park \\ Sung Hoon $\mathrm{Kim}^{1 *}$ and Sung-Rae Cho $\mathrm{C}^{2,3,6,7 *}$
}

'Department and Rehabilitation Medicine, Yonsei University Wonju College of Medicine, Wonju, South Korea, ${ }^{2}$ Department and Research Institute of Rehabilitation Medicine, Yonsei University College of Medicine, Seoul, South Korea, ${ }^{3}$ Brain Korea 21 PLUS Project for Medical Science, Yonsei University, Seoul, South Korea, ${ }^{4}$ Department of Medicine, Yonsei University College of Medicine, Seoul, South Korea, ${ }^{5}$ Department of Rehabilitation Medicine, Graduate School Yonsei University Wonju College of Medicine, Wonju, South Korea, ${ }^{6}$ Yonsei Stem Cell Center, Avison Biomedical Research Center, Seoul, South Korea, ${ }^{7}$ Rehabilitation Institute of Neuromuscular Disease, Yonsei University College of Medicine, Seoul, South Korea

Repetitive transcranial magnetic stimulation (rTMS) is a non-invasive therapy that has been implicated in treatment of serious neurological disorders. However, the neurobiological mechanisms underlying the effects of rTMS remain unclear. Therefore, this study examined the differential effects of repetitive magnetic stimulation (rMS) in an in vitro neuronal model of ischemia/reperfusion (I/R) injury, depending on low and high frequency. Neuro-2a cells were differentiated with retinoic acid and established for in vitro neuronal model of I/R injury under a subsequent $3 \mathrm{~h}$ of oxygen and glucose deprivation/ reoxygenation (OGD/R) condition. After the I/R injury, the differentiated neuronal cells were stimulated with rMS on day 1 and randomly divided into three groups: OGD/ R+sham, OGD/R+low-frequency, and OGD/R+high-frequency groups. High-frequency rMS increases cell proliferation through activation of extracellular signal-regulated kinases and AKT-signaling pathway and inhibits apoptosis in OGD/R-injured cells. Furthermore, high-frequency rMS increases $\mathrm{Ca}^{2+}$-calmodulin-dependent protein kinase II (CaMKII)-cAMP-response element binding protein (CREB) signaling pathway, further leading to alternation of brain-derived neurotrophic factor expression and synaptic plasticity in OGD/R injured cells. These results verified the neurobiological mechanisms of frequency-dependent rMS in I/R injury-treated neuronal cells. These mechanisms will help develop more powerful and credible rTMS stimulation treatment protocols.

\begin{abstract}
Keywords: repetitive magnetic stimulation, in vitro neuronal model of ischemia/reperfusion injury, extracellular signal-regulated kinases and AKT signaling pathway, apoptosis, $\mathrm{Ca}^{2+}$-calmodulin-dependent protein kinase IIcAMP-response element binding protein signaling pathway, brain-derived neurotrophic factor, synaptic plasticity, high frequency
\end{abstract}

\section{INTRODUCTION}

Magnetic stimulation produces current flow in the nerve tissue and causes neuronal depolarization $(1,2)$. Transcranial magnetic stimulation (TMS) generates current flow in the brain without direct contact with the scalp and can be used to assess and control the excitability of certain regions of the brain $(1,3)$. When induced at a regular frequency, these TMS pulses are called repetitive transcranial magnetic stimulation (rTMS) (4). 
rTMS is a non-invasive and less painful method to induce brain stimulation with no significant side effects $(1,5)$. rTMS is used as a treatment for a wide range of neurologic diseases, such as stroke and movement disorders, psychiatric diseases, and pain syndromes (6).

Several studies have demonstrated that the excitability of the cortex can be differentially modulated by intensity, frequency, and the overall pattern of the rTMS (3). Frequency is an important factor that can control cortical excitability. High-frequency $(>3 \mathrm{~Hz})$ stimulation usually has an effect of facilitation while lowfrequency $(\leq 1 \mathrm{~Hz})$ stimulation has a lowering effect of synaptic efficiency (7-11).

In stroke patients, the motor dysfunction of paretic limb is accompanied by decreased ipsilesional cortical excitability and increased interhemispheric inhibition (IHI) due to the increased contralesional cortical excitability (12). Therefore, rTMS in stroke patients can improve the function of paretic limb by increasing ipsilesional cortical excitability by applying high frequency rTMS to ipsilesional hemisphere (13-15). There are also several studies that improve the excitability of the ipsilesional cortex via the reduction of the IHI by applying low frequency rTMS to the contralesional hemisphere to improve the function of the paretic limb (16-20).

Furthermore, rTMS treatment is known to affect the regulation of brain plasticity in ischemic stroke patients (21). There are several studies to support neurotrophic factor-mediated brain plasticity as to a mechanism of stroke rehabilitation, and it is known that the expression of brain-derived growth factor (BDNF), which plays an important role in brain plasticity, changes in association with synaptic activity (22). In addition, several in vitro and in vivo studies have shown that rTMS affects the expression of various neurotrophic/growth factors, including BDNF, and neuroblastoma cell proliferation, which has been verified by the various frequencies of rTMS (23-25).

In ischemic stroke, brain injury is caused by ischemia as well as cell damage induced by reperfusion injury (26). Oxygen and glucose deprivation/reoxygenation (OGD/R) is well established in an in vitro model for the study of ischemic/reperfusion (I/R) injury of neurons $(27,28)$. A previous research confirms that the injury induced by OGD/R can mimic the I/R injury in an in vivo model of ischemic stroke (29).

Although considerable research has been done on the therapeutic use of rTMS for brain ischemic injury, the precise mechanism is still elusive. Therefore, to understand the therapeutic effect and mechanism of rTMS, it is necessary to combine the mechanism based on brain plasticity. In this study, we aimed to investigate the differential effects of repetitive magnetic stimulation (rMS) depending on frequency in an in vitro neuronal model of I/R injury using OGD/R.

\section{MATERIALS AND METHODS}

\section{Cell Cultures}

Neuro-2a (N2a) cells were purchased from American Type Culture Collection biotechnology (ATCC, Manassas, VA, USA). $\mathrm{N} 2$ a cells were derived from mouse neuroblastoma, which exhibits properties of neuronal stem cells and could differentiate into neuronal cells when treated with retinoic acid (RA). N2a cells were maintained in growth medium, which were Dulbecco's Modified Eagle Medium (DMEM; Hyclone, Logan, UT, USA) containing $10 \%$ fetal bovine serum (FBS; Serum Source International, Charlotte, NC, USA) and 1\% Penicillin-Streptomycin solution (Gibco, Rockville, MD, USA), in a humidified $5 \% \mathrm{CO}_{2}$ atmosphere at $37^{\circ} \mathrm{C}$. When $\mathrm{N} 2$ a cells reached $70-80 \%$ confluency, the medium was changed into differentiation medium, which contain $2 \%$ FBS and $20 \mu \mathrm{M}$ of RA in DMEM, for 4 days. Differentiated N2a cells were maintained in a humidified atmosphere of $5 \% \mathrm{CO}_{2}$ at $37^{\circ} \mathrm{C}$, and the differentiation medium was changed every 2 days.

\section{OGD/R and rMS}

The following procedures have been adapted from previous studies (29-31). Confluent-differentiated N2a cells were washed three times with phosphate-buffered saline (PBS) and the differentiation medium was replaced with deoxygenated, glucose-free balanced salt solution (Gibco), and transferred to a hypoxic chamber $\left(\mathrm{O}_{2}\right.$ tension 1\%) for $3 \mathrm{~h}$. Following OGD, injured cells were replaced with growth medium and stimulated with customized rMS (Bicon-1000Pro, Mcube Technology, Seoul, Korea). The magnetic coil (70-mm diameter) was placed and positioned $1 \mathrm{~cm}$ away from the cell culture dish. OGD/R cells were divided into three groups, as the OGD/R+sham group (placing the culture dishes without magnetic stimulation), the $\mathrm{OGD} / \mathrm{R}+$ low-frequency group $(0.5 \mathrm{~Hz}$ stimulation, on-off interval of $3 \mathrm{~s}$ ), and the OGD/ $\mathrm{R}+$ high-frequency group ( $10 \mathrm{~Hz}$ stimulation, on-off interval of $3 \mathrm{~s}$ ) for $10 \mathrm{~min}$. After the stimulation, cells were incubated in a humidified atmosphere of $5 \% \mathrm{CO}_{2}$ at $37^{\circ} \mathrm{C}$. After $24 \mathrm{~h}$, OGD/ $\mathrm{R}+\mathrm{rMS}$ cells were harvested using $0.25 \%$ trypsin-EDTA (Gibco). The experimental schedule is presented in Figure 1. All procedures of the cells were observed under microscope and changed morphology was photographed with a digital imaging system (Eclipse TS100; Nikon USA, Melville, NY, USA) in Figure 2A.

\section{Cell Proliferation}

To analyze the proliferation of the cells, the number of OGD/ $\mathrm{R}+\mathrm{rMS}$ cells was calculated with an advanced detection and accurate measurement (ADAM) automatic cell counter (NanoEnTek Inc., Seoul, South Korea).

\section{RNA Preparation}

Total RNA was prepared in the whole cell lysates using TRIzol reagent (Invitrogen Life Technologies, Carlsbad, CA, USA) according to the manufacturer's instructions. A nanodrop spectrophotometer (Thermo Fisher Scientific, Waltham, MA, USA) were used to confirm the quality and quantity of extracted RNA.

\section{Quantitative Real-Time Reverse Transcription Polymerase Chain Reaction (qRT-PCR)}

To examinemRNA expression, qRT-PCR wasconducted. ReverTra Ace ${ }^{\circledR}$ qPCR RT Master Mix with gDNA Remover (Toyobo, Osaka, Japan) was used to synthesize cDNA with total RNA. The procedures were according to the manufacturer's instructions. qPCR BIO SyGreen Mix Hi-ROX (PCR BIOSYSTEMS, London, UK) was used to confirm the mRNA expression for genes of interest 


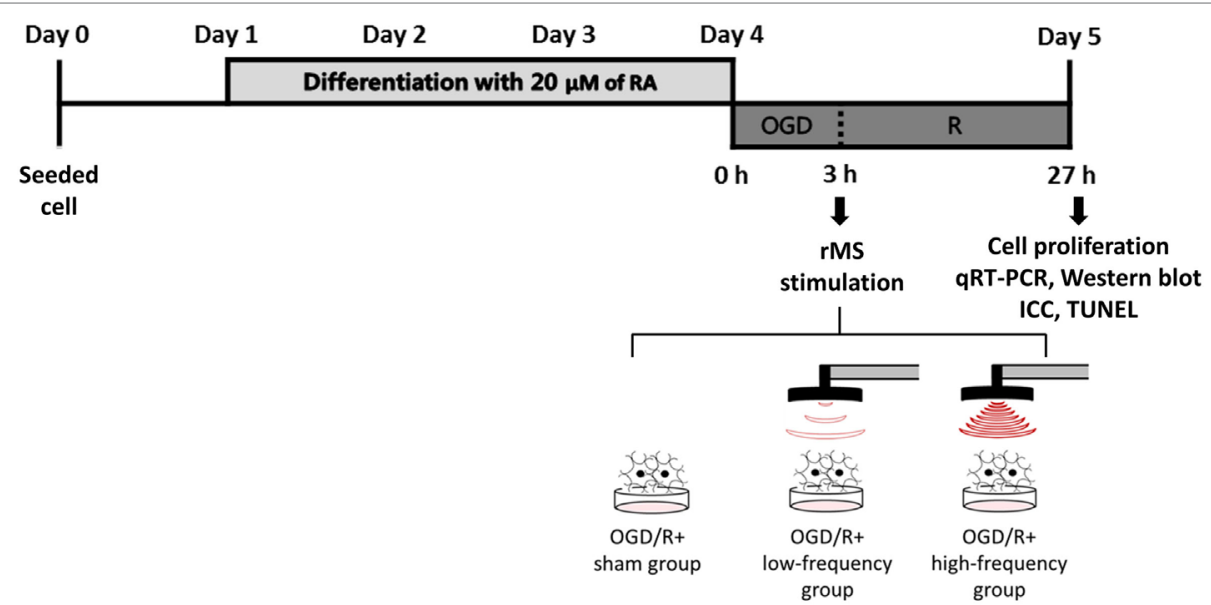

FIGURE 1 | The experimental timeline of oxygen and glucose deprivation/reoxygenation (OGD/R) exposure and rMS stimulation. On day 0, the equal amount of Neuro-2a (N2a) cells were seeded in growth medium, which contains 10\% fetal bovine serum (FBS) and 1\% Penicillin-Streptomycin solution. At 70-80\% confluency, the growth medium of N2a cells was changed into differentiation medium, which contains $20 \mu M$ of retinoic acid (RA) in Dulbecco's Modified Eagle Medium (DMEM) for 4 days. After washing three times with PBS, the differentiation medium of N2a cells was changed into deoxygenated, glucose-free balanced salt solution (Gibco) and placed into a hypoxic chamber $\left(\mathrm{O}_{2}\right.$ tension $\left.1 \%\right)$ for $3 \mathrm{~h}$. After this OGD injury, the cells were placed with medium and received on-off interval of $3 \mathrm{~s}$ stimulation for $10 \mathrm{~min}$. After the stimulation, the cells were incubated in a humidified atmosphere of $5 \% \mathrm{CO}_{2}$ at $37^{\circ} \mathrm{C}$. After $24 \mathrm{~h}, \mathrm{OGD} / \mathrm{R}+\mathrm{rMS}$ cells were harvested for cell proliferation analysis, qRT-PCR, Western blot, ICC, and TUNEL assay. RA, retinoic acid; OGD/R, oxygen and glucose deprivation/reperfusion; rMS, repetitive magnetic stimulation; qRT-PCR, quantitive real-time reverse transcription polymerase chain reaction; ICC, immunocytochemistry; TUNEL, terminal dUTP nick end-labeling.

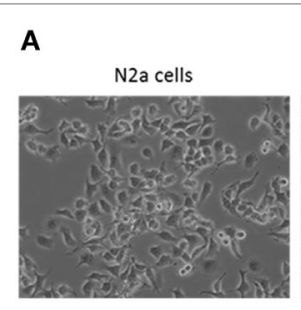

$\mathbf{B}$

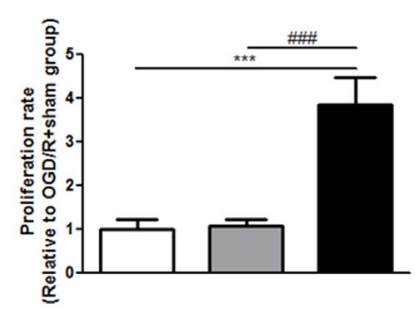

D

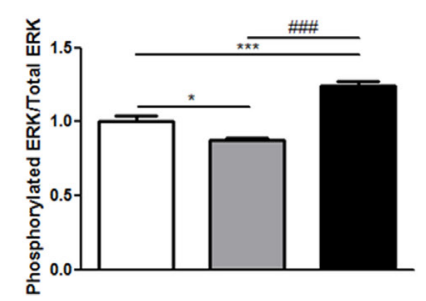

$\square$ OGD/R+sham group

$\square O G D / R+$ low-frequency group

- OGD/R+high-frequency group
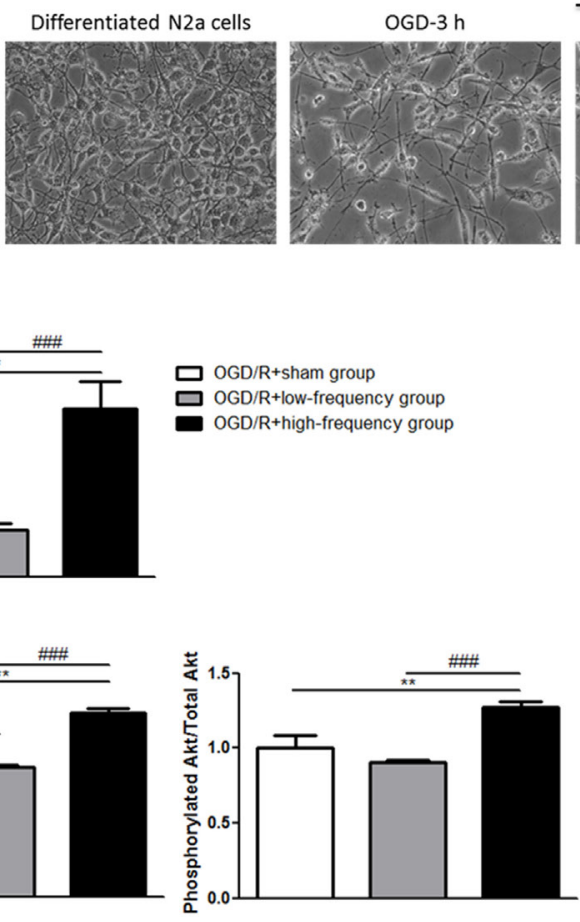

OGD/R+rMS cells

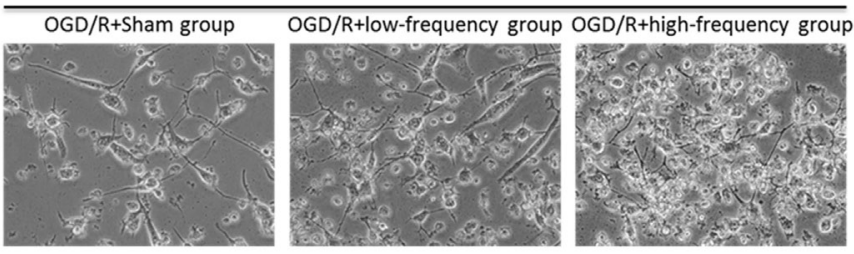

C

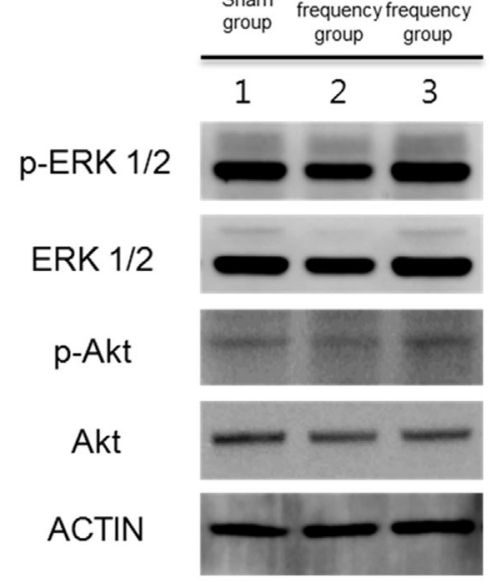

FIGURE 2 | High-frequency repetitive magnetic stimulation (rMS) increases proliferation through the extracellular signal-regulated kinase (ERK) and AKT signaling pathway following oxygen and glucose deprivation/reoxygenation (OGD/R) injury. (A) Changed morphology of the cells was observed under microscope and photographed with a digital imaging system. (B) Bar graphs were shown for the proliferation rate of rMS stimulation following OGD/R injury. The white bars indicate OGD/R+sham group, the gray bars indicate OGD/R+low-frequency group, and the black bars indicate OGD/R+high-frequency group. Proliferation rate was represented as the mean \pm SEM (OGD/R+sham group as control). ${ }^{* \star} p<0.001$ comparison with the OGD/R+sham group. ${ }^{\# \# \# ~} p<0.001$ comparison with the OGD/ R+low-frequency group. (C) Western blot analysis with antibodies against p-ERK, t-ERK, p-AKT, t-AKT, and ACTIN. (D) Comparison of relative expression for $p-E R K / E R K$ and $p-A K T / A K T$ from the OGD/R+rMS-treated group versus the OGD/R+sham group. All results are expressed as means \pm SEM. ${ }^{*}<<0.05$, ${ }^{\star \star} p<0.01$, and ${ }^{\star \star \star} p<0.001$ comparison with the OGD/R+sham group. $\# \#<0.001$ comparison with the OGD/R+low-frequency group. 
TABLE 1 | Primers used for quantitative real-time reverse transcription polymerase chain reaction (qRT-PCR)

\begin{tabular}{|c|c|c|}
\hline Gene symbol & Forward primer $\left(5^{\prime} \rightarrow 3^{\prime}\right)$ & Reverse primer $\left(5^{\prime} \rightarrow 3^{\prime}\right)$ \\
\hline GRIN1 & $\begin{array}{l}\text { CAG GAT CGT CAG } \\
\text { GCA AGA CA }\end{array}$ & $\begin{array}{l}\text { CCA AGC AAC TGA } \\
\text { GGG TCC Tा }\end{array}$ \\
\hline CaMKII $\alpha$ & $\begin{array}{l}\text { TGC TGC TCT TाC } \\
\text { TCA CGC TG }\end{array}$ & $\begin{array}{l}\text { TCA ATG GTG GTG } \\
\text { TTG GTG CT }\end{array}$ \\
\hline CaMKII反 & $\begin{array}{l}\text { TGC ACC TGG TAG } \\
\text { GGG ACG AT }\end{array}$ & $\begin{array}{l}\text { GAA TAC AGG GTG } \\
\text { GCT TGA TGG GT }\end{array}$ \\
\hline$B D N F$ & $\begin{array}{l}\text { GGG TCA CAG CGG } \\
\text { CAG ATA AA }\end{array}$ & $\begin{array}{l}\text { ATT GCG AGT TCC } \\
\text { AGT GCC TT }\end{array}$ \\
\hline Synaptophysin & $\begin{array}{l}\text { GTG CCA ACA AGA } \\
\text { CGG AGA GT }\end{array}$ & $\begin{array}{l}\text { CAC CCG AGG AGG } \\
\text { AGT AGT CA }\end{array}$ \\
\hline PSD-95 & $\begin{array}{l}\text { TCC CCA TाT TCT } \\
\text { CCC ACA CAC }\end{array}$ & $\begin{array}{l}\text { ACG GCG TGG GGA } \\
\text { GTT ATG AT }\end{array}$ \\
\hline GAPDH & $\begin{array}{l}\text { CAT CAC TGC CAC } \\
\text { CCA GAA GAC TG }\end{array}$ & $\begin{array}{l}\text { ATG CCA GTG AGC } \\
\pi T C \text { CCG TTC AG }\end{array}$ \\
\hline
\end{tabular}

Grin 1, glutamate receptor ionotropic N-methyl-D-aspartate 1; CaMKI/ $\alpha$, calcium/ calmodulin-dependent protein kinase II alpha; CaMKII/, calcium/calmodulin-dependent protein kinase type II subunit delta; BDNF, brain-derived neurotrophic factor; PSD-95, postsynaptic density protein-95; GAPDH, glyceraldehyde-3-phosphate dehydrogenase.

in a StepOnePlus Real-Time PCR System (Applied Biosystems, Foster City, CA, USA). Data analysis was performed using the $2^{-\triangle \Delta C T}$ method (32). Primers used for qRT-PCR are described in Table 1.

\section{Western Blot}

To confirm the protein expression, whole cell lysates were homogenized and dissolved with radioimmunoprecipitation assay buffer (Thermo Scientific) containing protease and phosphatase inhibitors (Abcam, Cambridge, MA, USA). The BCA ${ }^{\mathrm{TM}}$ Protein Assay Kit (Thermo Scientific) was used to quantify the total protein. The samples were denatured and separated by $4-12 \%$ Bis-Tris gels in $1 \times$ NuPage MES SDS Running Buffer (Invitrogen, Eugene, OR, USA). Proteins were transferred at $4^{\circ} \mathrm{C}$ onto a polyvinylidene difluoride membrane (Invitrogen) in NuPage Transfer Buffer (Invitrogen) with $20 \%$ (vol/vol) methanol. Membranes were blocked and then incubated overnight at $4^{\circ} \mathrm{C}$ with the following antibodies: Anti-p-Erk1/2 (1:1,000 dilution, Santa Cruz Biotechnology, Santa Cruz, CA, USA), Anti-t-Erk1/2 (1:1,000 dilution, Santa Cruz Biotechnology), Anti-p-AKT (1:1,000 dilution, Santa Cruz Biotechnology), Anti-t-AKT (1:1,000 dilution, Santa Cruz Biotechnology), Anti-BAX (1: 1,000 dilution, Santa Cruz Biotechnology), Anti-Bcl-2 (1:1,000 dilution, Santa Cruz Biotechnology), Anti-Cleaved-caspase-3 (1:1,000 dilution, Cell Signaling Technology, Danvers, MA, USA), Anti-Pro-caspase-3 (1:1,000 dilution, Santa Cruz Biotechnology), Anti- $N$-methyl-Daspartate receptors1 (NMDAR1; 1: 1,000 dilution, Invitrogen), Anti-CaMKII (1:1,000 dilution, Abcam), Anti-CREB (1:1,000 dilution, Santa Cruz Biotechnology), Anti-p-CREB (1:1,000 dilution, Santa Cruz Biotechnology), Anti-BDNF (1:1,000 dilution, Abcam), and Anti-ACTIN (1:5,000 dilution, Santa Cruz Biotechnology). The next day, blots were washed three times with TBS plus Tween 20 and incubated at room temperature for $1 \mathrm{~h}$ with horseradish peroxidase-conjugated secondary antibodies
(1:4,000 dilution, Santa Cruz). An enhanced chemiluminescence detection system (Amersham Pharmacia Biotech, Little Chalfont, UK) was used to visualize the protein.

\section{Immunocytochemistry (ICC)}

To confirm the expression of BDNF, Synaptophysin and postsynaptic density protein-95 (PSD-95) in differentiated N2a cells were seeded into $0.2 \%$ gelatin (Sigma-aldrich, St. Louis, MO, USA) in PBS coated 4-well with OGD/R+rMS stimulation as described above. Cells were stained with Anti-BDNF (1:400 dilution, Abcam), Anti-Synaptophysin (1:400 dilution, Abcam), and Anti-PSD-95 (1:400 dilution, Abcam) and incubated with Alexa Fluor ${ }^{\circledR}$ (1:400, Invitrogen) secondary antibody. Samples were mounted on glass slides with fluorescent mounting medium with 4',6-diamidino-2-phenylindole (DAPI; Vectorshield, Vector Laboratories, Burlingame, CA, USA) for imaging using the Zeiss Axio Imager M2 (Carl Zeiss, Gottingen, Germany) fluorescence microscope.

\section{Terminal dUTP Nick End-Labeling (TUNEL) Assay}

For analysis of apoptosis, differentiated N2a cells were seeded into gelatin (Sigma-aldrich) coated 4-well. OGD/R and rMS stimulation were performed as described above. Colorimetric TUNEL assay (Promega, Madison, WI, USA) was conducted according to the manufacturer's protocol.

\section{Statistical Analysis}

All experiments were conducted at least three independent replications. The results were expressed as means \pm SEM. The Statistical Package for Social Sciences version 23.0 was used for statistical analysis. The one-way analysis of variance, followed by Bonferroni post hoc multi-comparison test was carried out to confirm the statistical results. Statistical differences were considered significant when $p<0.05$.

\section{RESULTS}

\section{High-Frequency rMS Increases Cell Proliferation through the Activation of Extracellular Signal-Regulated Kinase (ERK) and AKT Signaling Pathway after OGD/R Injury}

In the previous study (24), rMS affects cell proliferation in the neuroblastoma cells. Therefore, we evaluated cell proliferation with an ADAM, the automatic cell counting machine, after the stimulation with or without rMS following OGD/R injury. After $24 \mathrm{~h}$ following OGD/R+rMS stimulation, the proliferation rate of the $\mathrm{OGD} / \mathrm{R}+$ low-frequency group $(1.06 \pm 0.16)$ was not significantly different compared to the OGD/R+sham group (Figure 2B). However, in the $\mathrm{OGD} / \mathrm{R}+$ high-frequency group, proliferation rate was significantly increased compared to the $\mathrm{OGD} / \mathrm{R}+$ sham group, and the proliferation rate and statistical value were as follows: $3.84 \pm 0.64, p<0.001$ (Figure 2B). In the samemanner, the proliferation rate of the OGD/R+high-frequency 
group was significantly increased compared to the OGD/R+lowfrequency group $(p<0.001)$ (Figure 2B).

Next, we investigated ERK and AKT pathway, which were known to play an important role in the development of synaptic plasticity and neurotrophic activity (33) as well as the regulation of growth and proliferation $(24,34)$, by western blot analysis (Figure 2C). The OGD/R+low-frequency group showed the decreased expression of $\mathrm{p}$-ERK and p-AKT compared to the OGD/ $\mathrm{R}+$ sham group and the expression values were as follows: $\mathrm{p}-\mathrm{ERK} /$ ERK $(0.88 \pm 0.01, p<0.05), \mathrm{p}-\mathrm{AKT} / \mathrm{AKT}(0.90 \pm 0.01, p<0.01)$ (Figure 2D). By contrast, the $\mathrm{OGD} / \mathrm{R}+$ high-frequency group showed the significantly activated p-ERK and p-AKT expression compared to the $\mathrm{OGD} / \mathrm{R}+$ sham group, and the expression values were as follows: $\mathrm{p}$-ERK/ERK $(1.25 \pm 0.02, p<0.001)$ and $\mathrm{p}$-AKT/ AKT $(1.27 \pm 0.04, p<0.01)$ (Figure 2D). The OGD/R+highfrequency group also showed the significant increased expression of p-ERK and p-AKT compared to the OGD/R+low-frequency group and the expression values were as follows: $\mathrm{p}$-ERK/ERK $(p<0.001)$, p-AKT/AKT $(p<0.001)$ (Figure 2D).

Thus, we suggest that high frequency rMS increases cell proliferation via activation of ERK and AKT signaling pathway following OGD/R injury in differentiated neuronal cells.

\section{High-Frequency rMS Reduces Apoptotic Process after OGD/R Injury}

It has been well demonstrated that neuronal apoptosis is one of the hallmarks of cerebral ischemia/reperfusion (I/R) injury (35). We constructed the OGD/R injury in differentiated neuronal cells to mimic the in vivo cerebral I/R conditions. Apoptotic process was investigated using the protein expressions of apoptosisrelated proteins, such as $\mathrm{Bcl}-2$-associated $\mathrm{X}$ protein (BAX), Bcl-2, Cleaved caspase-3, and Pro-caspase-3 (Figure 3A). As shown in Figures $\mathbf{3 A}, \mathbf{B}$, the $\mathrm{OGD} / \mathrm{R}+$ high-frequency group showed significant decrease in the expression of pro-apoptotic proteins, such as BAX and Cleaved-caspase-3, while showing significant increase in the expression of anti-apoptotic proteins, as Bcl-2 and Pro-caspase- 3 , compared to the OGD/R+sham group. The expression values were as follows: $\operatorname{BAX}(0.50 \pm 0.08, p<0.001)$, Bcl-2 (1.29 $\pm 0.04, p<0.01)$, Cleaved-caspase-3 (0.28 \pm 0.04 , $p<0.001)$, and Pro-caspase-3 (1.36 $\pm 0.03, p<0.001)$. In the OGD/R+low-frequency group compared to the OGD/R+sham group, the expression of pro-apoptotic proteins, such as BAX and Cleaved-caspase-3, was increased, while the expression of anti-apoptotic proteins, such as Bcl-2 and Pro-caspase-3, was decreased. The expression values were as follows: BAX (1.32 \pm
A

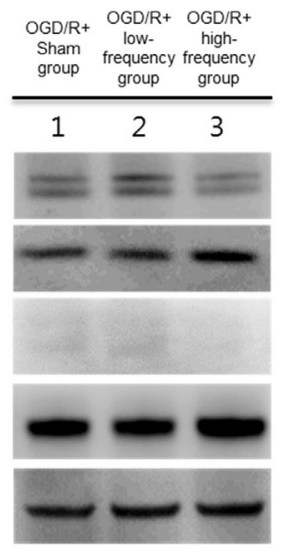

C

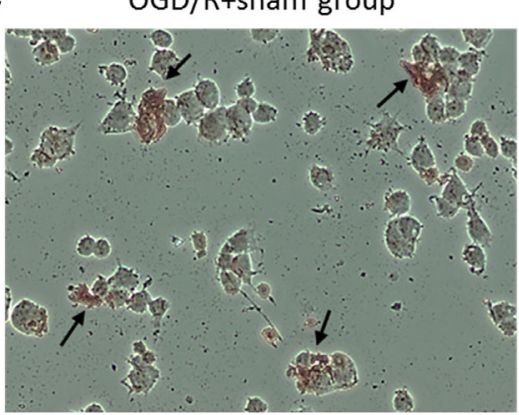

ACTIN
B
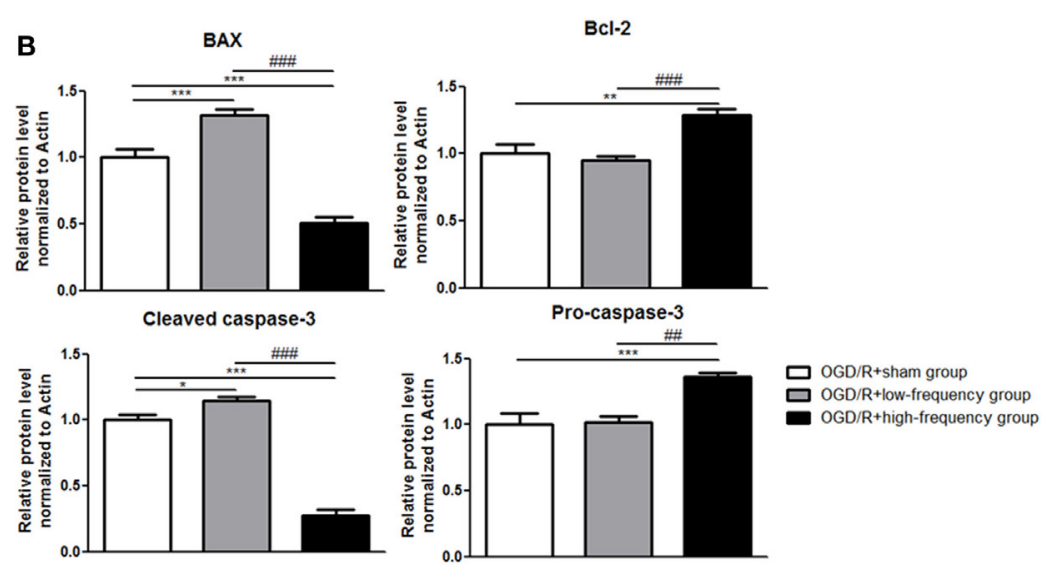

OGD/R+low-frequency group

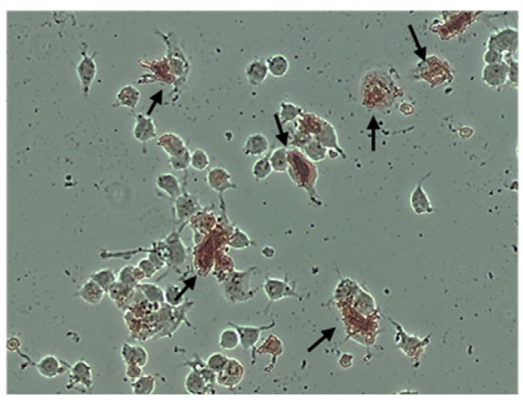

$\mathrm{OGD} / \mathrm{R}+$ high-frequency group

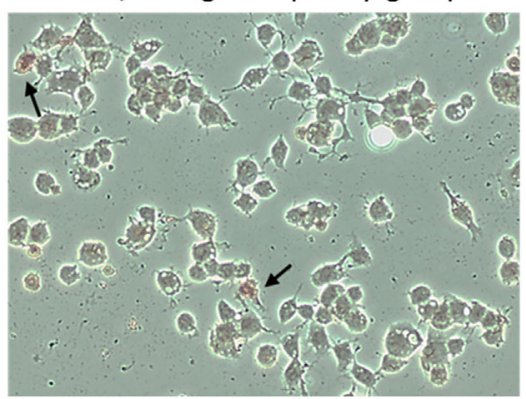

FIGURE 3 | High-frequency repetitive magnetic stimulation (rMS) inhibits apoptosis expression following oxygen and glucose deprivation/reoxygenation (OGD/R) injury. (A) Western blot analysis with antibodies against Bcl-2-associated X protein (BAX), Bcl-2, Cleaved caspase-3, and Pro-caspase-3. (B) Comparison of relative expression apoptosis protein from the OGD/R+rMS treated group versus the OGD/R+sham group. All results are expressed as means \pm SEM. ${ }^{*} p<0.05$,

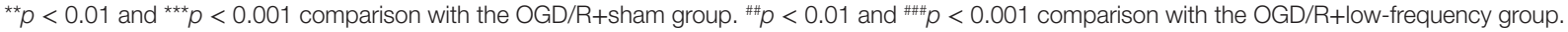
(C) Detection of apoptosis with terminal dUTP nick end-labeling (TUNEL) assay in the rMS stimulation following OGD/R injury. Black arrow indicates apoptotic nuclei following OGD/R injury in differentiated Neuro-2a (N2a) cells. 
$0.04, p<0.001)$, Bcl-2 (0.95 \pm 0.03$)$, Cleaved-caspase-3 (1.15 $\pm 0.02, p<0.05)$, and Pro-caspase-3 (1.02 \pm 0.05$)$. In the same manner, in the OGD/R+high-frequency group compared to the OGD/R+low-frequency group, the expression of pro-apoptotic proteins was statistically decreased, while the expression of anti-apoptotic proteins was statistically increased. The expression statistical values were as follows; $\operatorname{BAX}(p<0.001)$, Bcl-2 $(p<0.001)$, Cleaved-caspase-3 $(p<0.001)$, and Pro-caspase-3 $(p<0.01)$.

To further investigate the underlying mechanism associated with apoptosis, we used TUNEL assay (Figure 3C). The number of TUNEL-positive nuclei was much observed in the OGD/ $\mathrm{R}+$ low-frequency group compared to the OGD/R+sham group or the OGD/R+high-frequency group. On the other hand, there were few TUNEL-positive nuclei in the OGD/R+high-frequency group compared to the $\mathrm{OGD} / \mathrm{R}+$ sham group and the OGD/ $\mathrm{R}+$ low-frequency group.

These data suggest that high frequency rMS inhibits the progression of apoptosis following OGD/R injury in differentiated neuronal cells.

\section{High-Frequency rMS Increases $\mathrm{Ca}^{2+}-$ CaMKII-CREB Signaling Pathway after OGD/R Injury}

In our previous study, we confirmed with transcriptome analysis that high frequency rMS can activate $\mathrm{Ca}^{2+}-\mathrm{CaMKII-CREB}$ signaling pathway, thus increasing the expression of $\mathrm{p}$-CREB and BDNF via the activation of that signaling pathway in the neuronal cells. We further evaluated $\mathrm{Ca}^{2+}-\mathrm{CaMKII-CREB}$ signaling pathway following OGD/R+rMS stimulation. By qRT-PCR, in the OGD/R+low-frequency group compared to the OGD/R+sham group, the expression of GRIN1, CaMKII $\alpha$, and CaMKIIס was decreased (Figure 4A). The expression values as follows; GRIN1 $(0.71 \pm 0.15)$, CaMKII $\alpha(0.72 \pm 0.05, p<0.05)$, and CaMKII $\delta$ $(0.36 \pm 0.05, p<0.001)$. In the $\mathrm{OGD} / \mathrm{R}+$ high-frequency group, the expression of GRIN1, CaMKII $\alpha$, and CaMKII $\delta$ was significantly increased compared to the OGD/R+sham group (Figure 4A). The expression values were as follows: GRIN1 $(1.85 \pm 0.20, p<0.01)$, CaMKII $\alpha(1.27 \pm 0.04, p<0.05)$, and CaMKIIS $(1.28 \pm 0.06, p<0.01)$. Furthermore, in the OGD/

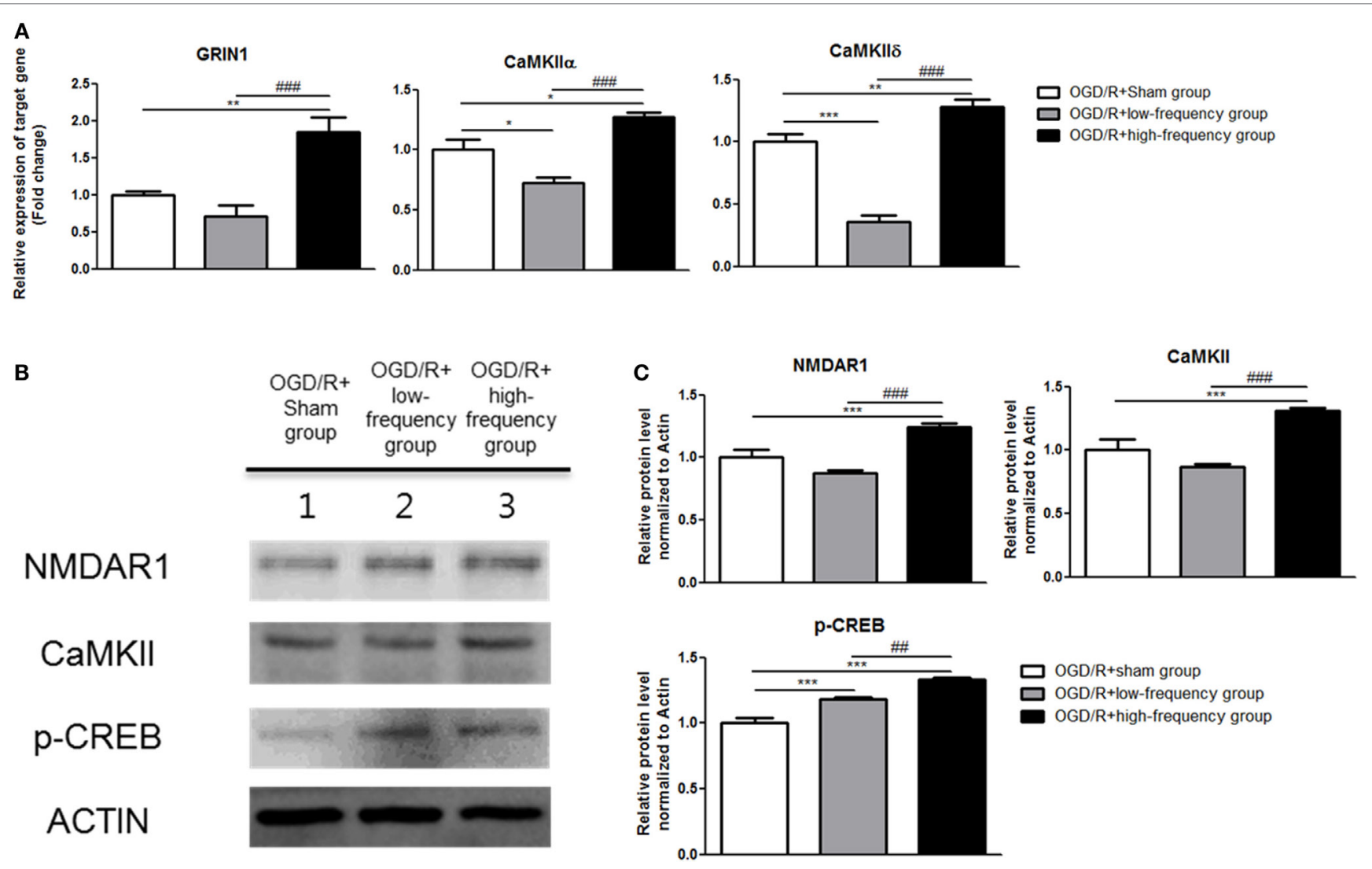

FIGURE 4 | High-frequency repetitive magnetic stimulation (rMS) activates $\mathrm{Ca}^{2+}$-calmodulin-dependent protein kinase II (CaMKII)-cAMP-response element binding

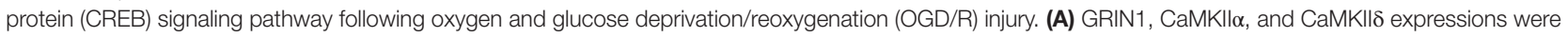
examined by quantitative real-time reverse transcription polymerase chain reaction. The relative expression of target genes was normalized by the OGD/R+sham group and was calculated using $2^{-\Delta \Delta C t}$ method. (B) Western blot analysis was performed using antibodies against N-methyl-D-aspartate receptors1(NMDAR1), CaMKII, p-CREB, and ACTIN (as control). (C) Comparison of relative expression apoptosis protein from the OGD/R+rMS-treated group versus the OGD/R+sham group. All results are expressed as means \pm SEM. ${ }^{*} p<0.05,{ }^{* *} p<0.01$, and ${ }^{* \star *} p<0.001$ comparison with the OGD/R+sham group. ${ }^{*} p<0.05,{ }^{* \#} p<0.01$, and $\# \#<0.001$ comparison with the OGD/R+low-frequency group. 
$\mathrm{R}+$ high-frequency group compared to the OGD/low-frequency group, the expression of GRIN1, CaMKII $\alpha$, and CaMKIIס was significantly increased (Figure 4A). The statistical values were as follows: GRIN1 $(p<0.001)$, CaMKII $\alpha(p<0.001)$, and CaMKII $\delta$ $(p<0.001)$.

Next, to further evaluate $\mathrm{Ca}^{2+}-\mathrm{CaMKII-CREB}$ signaling pathway, western blot was conducted (Figure 4B). In the OGD/ $\mathrm{R}+$ low-frequency group, the expression of $\mathrm{N}$-methyl-D-aspartate receptors1 (NMDAR1), CaMKII, and p-CREB was decreased or no difference was shown compared to the OGD/R+sham group (Figure 4C). The expression values as follows: NMDAR1 $(0.87 \pm 0.20)$, CaMKII $(0.86 \pm 0.02)$, and p-CREB (1.19 \pm 0.02 , $p<0.001)$. In the OGD/R+high-frequency group, the expression of NMDAR1, CaMKII, and p-CREB was increased compared to the $\mathrm{OGD} / \mathrm{R}+$ sham group (Figure $4 \mathrm{C}$ ). The expression values as follows: NMDAR1 $(1.25 \pm 0.03, p<0.001)$, CaMKII $(1.31 \pm$ $0.02, p<0.001)$, and $\mathrm{p}$-CREB $(1.33 \pm 0.01, p<0.001)$. In the OGD/R+high-frequency group, the expression of NMDAR1, CaMKII, and p-CREB was increased compared to the OGD/ $\mathrm{R}+$ low-frequency group (Figure 4C). The statistical values were as follows: NMDAR1 $(p<0.001)$, CaMKII $(p<0.001)$, and p-CREB $(p<0.01)$.

Taken together, these data suggest that high frequency of rMS activates $\mathrm{Ca}^{2+}-\mathrm{CaMKII-CREB}$ signaling pathway following $\mathrm{OGD} / \mathrm{R}$ injury in differentiated neuronal cells.

\section{High-Frequency rMS Increases BDNF Expression after OGD/R Injury}

In the same manner, we examined the expression of BDNF following OGD/R+rMS stimulation. By qRT-PCR, we found that in the OGD/R+low-frequency group, the expression of BDNF was significantly decreased compared to the OGD/R+sham group, and the expression value was as a follow: $\operatorname{BDNF}(0.36 \pm$ $0.05, p<0.001$ ) (Figure 5A). In the OGD/R+high-frequency group, the expression of BDNF was significantly increased compared to the $\mathrm{OGD} / \mathrm{R}+$ sham group and the expression value was as a follow: $\operatorname{BDNF}(1.33 \pm 0.04, p<0.001)$ (Figure 5A) Furthermore, in the OGD/R+high-frequency group compared to the OGD/R+low-frequency group, the expression of BDNF was significantly increased and the statistical value was as follow: BDNF $(p<0.001)$ (Figure 5A).

Then, we further evaluated BDNF expression with ICC analysis (Figure 5B). In the $\mathrm{OGD} / \mathrm{R}+$ high-frequency group, the protein level of BDNF is significantly higher than the OGD/ $\mathrm{R}+$ low-frequency or sham group. BDNF expression was significantly decreased, whereas high frequency rMS induces BDNF expression following OGD/R injury in differentiated neuronal cells.

We conclude that high frequency rMS increases BDNF expression via activation of $\mathrm{Ca}^{2+}-\mathrm{CaMKII}-\mathrm{CREB}$ signaling pathway following OGD/R injury in differentiated neuronal cells.
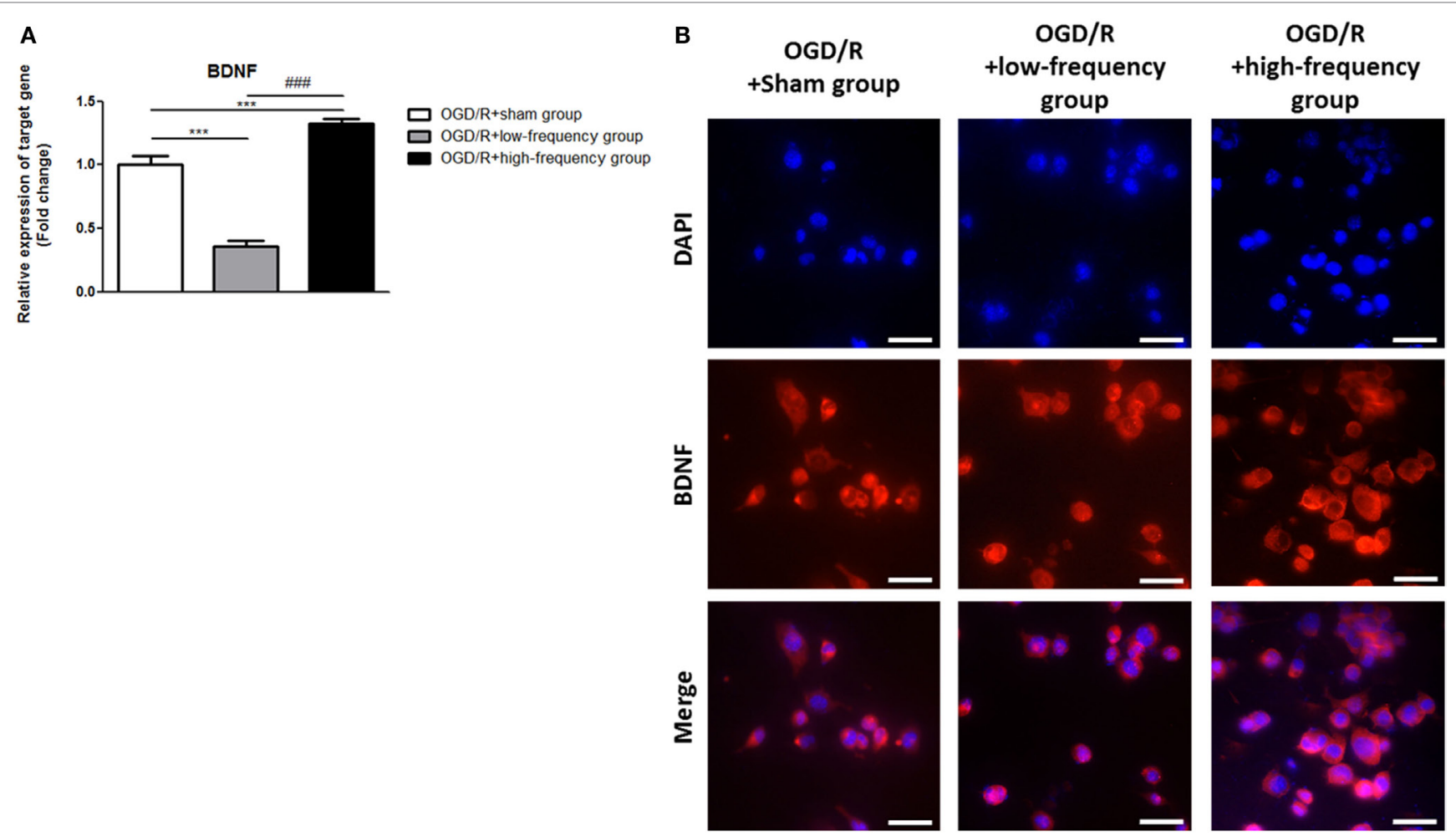

FIGURE 5 | High-frequency repetitive magnetic stimulation increase brain-derived neurotrophic factor (BDNF) expression following oxygen and glucose deprivation/ reoxygenation (OGD/R) injury. (A) BDNF mRNA expression was examined by quantitative real-time reverse transcription polymerase chain reaction (qRT-PCR). The relative expression of target gene was normalized by the OGD/R+sham group and was calculated using $2^{-\Delta \Delta C t}$ method. (B) Immunocytochemistry (ICC) was conducted to evaluate the level of BDNF. Scale bar: $50 \mu \mathrm{M}$, BDNF: Red, 4',6-diamidino-2-phenylindole (DAPI): Blue. 


\section{High-Frequency rMS Increases Synaptic Plasticity after OGD/R Injury}

It is reported that the expression of p-CREB and BDNF is related to the regulation of synaptic plasticity $(36,37)$. We next assessed synaptic plasticity following $\mathrm{OGD} / \mathrm{R}+\mathrm{rMS}$ stimulation. By qRT-PCR, in the OGD/R+low-frequency group, the expression of synaptophysin, as a presynaptic marker, and PSD-95, as a postsynaptic marker, was significantly decreased compared to the OGD/R+sham group and the expression values were as follows: Synaptophysin $(0.71 \pm 0.07)$ and PSD-95 $(0.41 \pm 0.05, p<0.01)$ (Figure 6A). In the OGD/R+high-frequency group, the expression of synaptophysin and PSD-95 was significantly increased compared to the $\mathrm{OGD} / \mathrm{R}+$ sham group and the expression values were as follows: Synaptophysin $(1.39 \pm 0.12, p<0.05)$ and PSD-95 $(1.38 \pm 0.04, p<0.05)$ (Figure 6A). In the OGD/R+highfrequency group compared to the $\mathrm{OGD} / \mathrm{R}+$ low-frequency group, the expression of synaptophysin and PSD-95 was significantly increased and the statistical values were as follows: Synaptophysin $(p<0.001)$ and PSD-95 $(p<0.001)$ (Figure 6A).

Next, we performed ICC analysis to evaluate synaptic plasticity (Figure 6B). In the OGD/R+low-frequency group, the protein level of synaptophysin and PSD-95 was not significantly different compared to the $\mathrm{OGD} / \mathrm{R}+$ sham group. On the other hand, the protein level of synaptophysin and PSD-95 was significantly increased in the $\mathrm{OGD} / \mathrm{R}+$ high-frequency group compared to the OGD/R+low-frequency or sham group.

These data indicated that high frequency rMS increases synaptic plasticity following OGD/R injury in differentiated neuronal cells.

\section{DISCUSSION}

Several studies have been conducted to study the effect of rMS on neuronal recovery in the I/R injury model $(3,25,38,39)$. However,

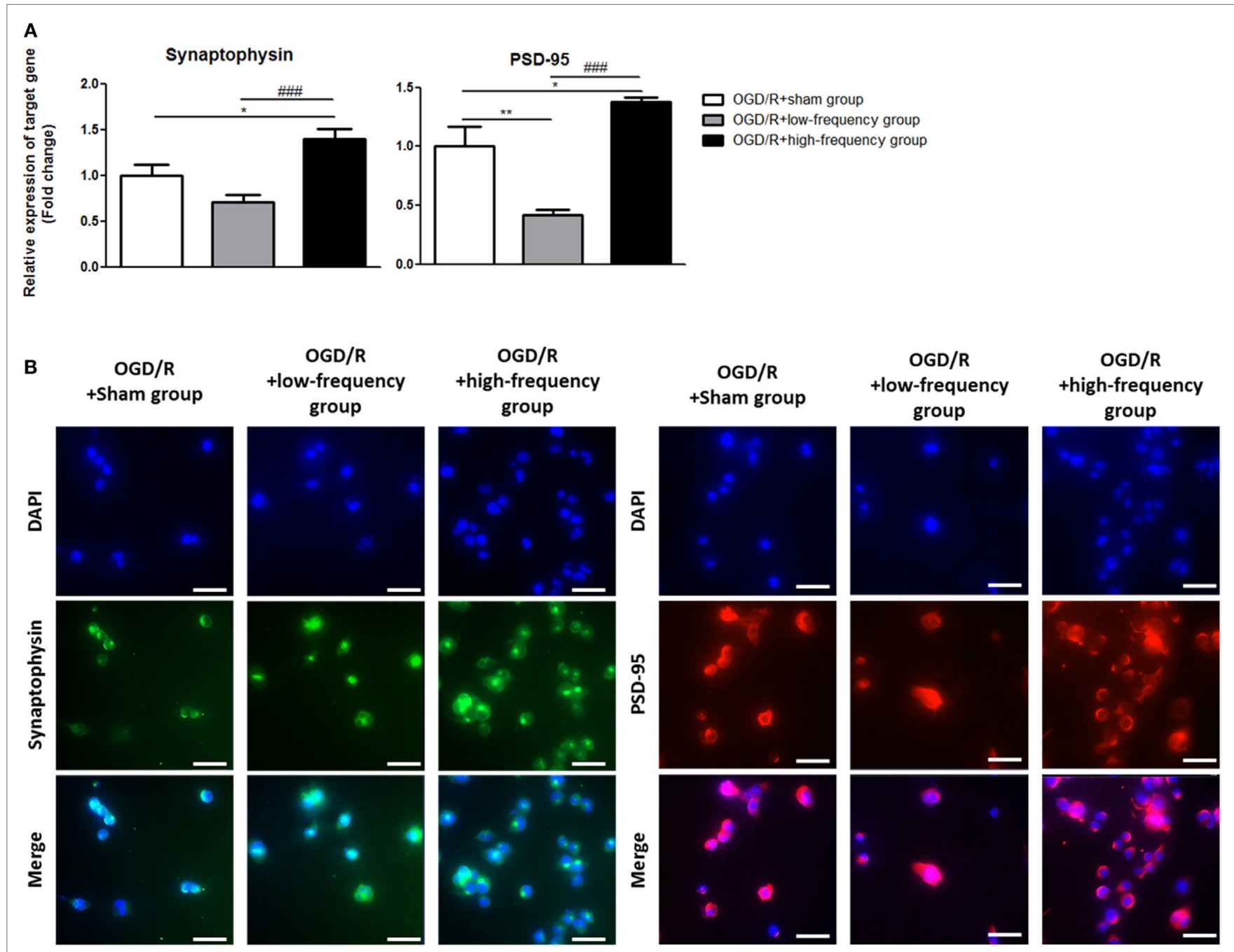

FIGURE 6 | High-frequency repetitive magnetic stimulation increases synaptic plasticity following oxygen and glucose deprivation/reoxygenation (OGD/R) injury. (A) Synaptophysin and postsynaptic density protein-95 (PSD-95) expressions were examined by qRT-PCR. The relative expression of target genes was normalized with respect to the OGD/R+sham group and was calculated using $2^{-\Delta \Delta C t}$ method. (B) Immunocytochemistry (ICC) was conducted to evaluate the level of synaptophysin and PSD-95. Scale bar: 50 M, synaptophysin: Green, PSD-95: Red, 4',6-diamidino-2-phenylindole (DAPI): Blue. 
the neurobiological mechanism of rMS on the frequency difference in the I/R injury model has not been fully understood. Frequency-dependent stimulation with the same duration has been reported as the primary treatment regime of rMS (38-43). In this study, we developed an I/R injury model using neuronal cells and then applied different frequencies of rMS to it.

It was found that in the high frequency of rMS, cell proliferation was increased, and apoptotic process was decreased compared to the sham or low-frequency rMS following I/R injury. We also verified that the activation of the $\mathrm{Ca}^{2+}-\mathrm{CaMKII-CREB}$ signaling pathway resulted in increased synaptic plasticity via increasing the expression of BDNF. These results are consistent with the previous studies using neuroblastoma cells, which were transformed neuron-liked cells $(23,24)$.

In this study, we constructed in vitro I/R injury model to verify accurate therapeutic mechanisms of rMS. When high-frequency rMS was applied to neuronal cells model with I/R injury, activation of the ERK and AKT signaling pathway promoted cell proliferation. These results are consistent with studies using neuroblastoma cells; the effects of rMS-induced cell proliferation were mediated by various growth factors, proliferation-, and survival-associated ERK and AKT (24). ERK and AKT signaling has been known to play an important role in the proliferation and maturation of neural progenitor cells $(43,44)$ as well as the regulation of migration of neuroblasts (45).

Next, we verified that high frequency of rMS inhibits the progression of apoptosis in differentiated neuronal cells model with $\mathrm{I} / \mathrm{R}$ injury. This is in agreement with other in vivo studies. In a study of high-frequency rTMS using a subacute cerebral ischemic rat model, it was suggested that the anti-apoptotic mechanism is the main mechanism of rTMS treatment (39). Another study of the hippocampus area in an ischemic stroke rat model showed that high-frequency rTMS inhibited neuronal apoptosis in ischemic hemispheres (41). In this study, we verified in vitro that high-frequency rMS inhibits the progression of apoptosis, indicating a protective role for the neuronal cells, which have been subjected to I/R injury.

In the brain, BDNF is known to improve neuronal survival, synaptogenesis, angiogenesis, and neurogenesis to regulate neuroplasticity $(22,42,46,47)$. It is also known that rMS affects the expression of BDNF in cultured hippocampal neurons (23). In particular, high frequency of rMS has been shown to increase BDNF expression $(24,25)$. Our previous study has also shown that the increased expression of BDNF by high-frequency rMS is due to the activation of the $\mathrm{Ca}^{2+}-\mathrm{CaMKII-CREB}$ signaling pathway.

In this study, using the same method as our previous study, we verified that BDNF expression was increased by the activation of the $\mathrm{Ca}^{2+}-\mathrm{CaMKII}-\mathrm{CREB}$ signaling pathway with high-frequency stimulation in the I/R injury model as well. We also examined that synaptophysin, a presynaptic marker, and PSD-95, a postsynaptic maker, were both found to increase in high-frequency rMS, thereby improving BDNF-mediated synaptic plasticity. It is thought that, when high-frequency rMS is applied, the various effects due to the increase expression of BDNF may act as a restoring mechanism of the function after I/R injury.

In this study, low-frequency rMS to neuronal cells with I/R injury showed no direct positive effects in cell proliferation, anti-apoptosis, and synaptic plasticity. Previous studies in stroke patients suggested that low-frequency rTMS stimulates
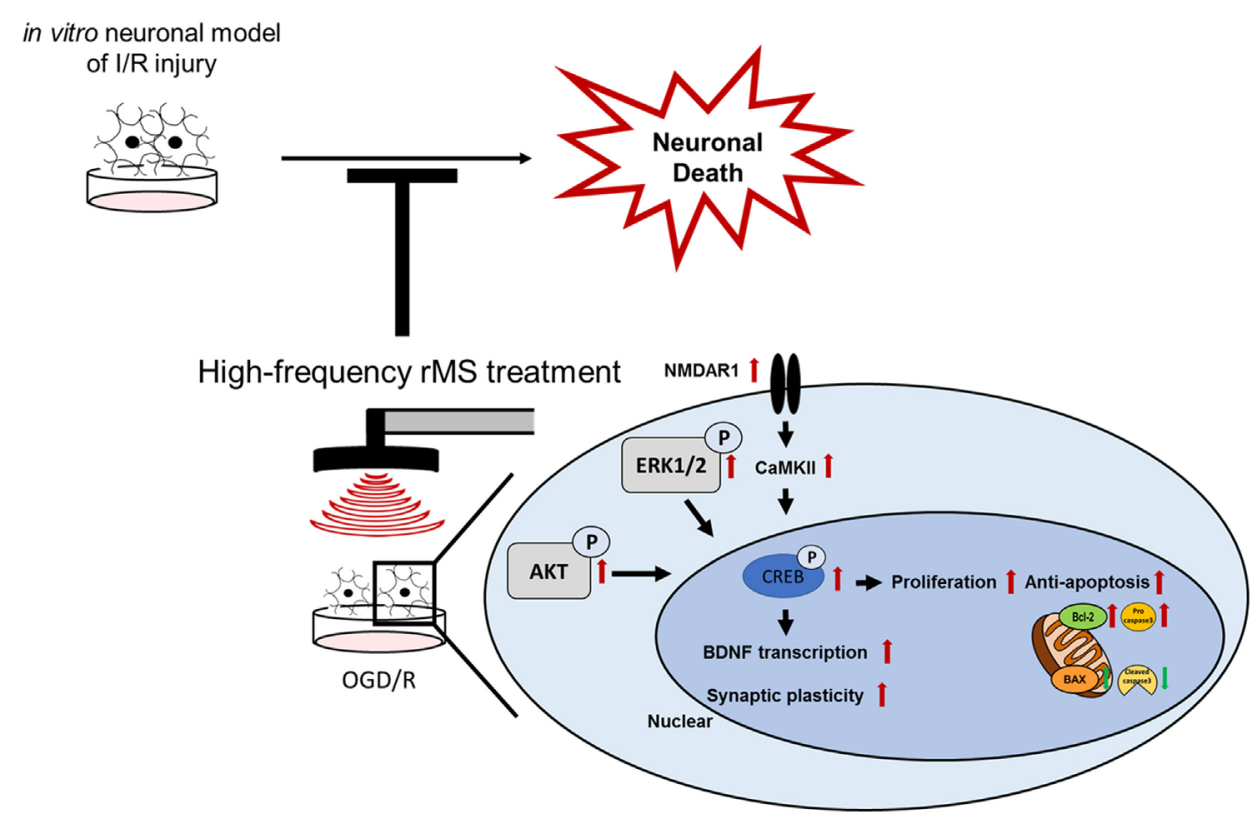

FIGURE 7 | Schematic diagram of the therapeutic mechanisms of repetitive magnetic stimulation (rMS) following ischemia/reperfusion (I/R) injury. High-frequency

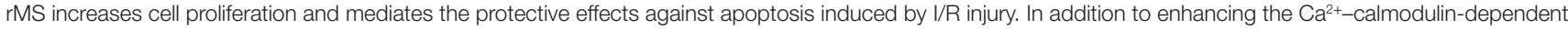
protein kinase II (CaMKII)-CAMP-response element binding protein (CREB) signaling pathway by high-frequency rMS, it also results in activation of brain-derived neurotrophic factor (BDNF) expression and synaptic plasticity in I/R injury. 
the contralesional hemisphere rather than the lesion side, exerting the positive indirect effect and lowering hyper-excitability (48). Therefore, additional follow-up studies will be needed to investigate the molecular mechanism of low frequency rTMS in stroke.

These findings call for further studies on varying degrees of cell regeneration after rMS application, by comparing groups applied with low- and high-frequency rMS after I/R injury and groups neither applied with rMS nor subjected to I/R injury. It is necessary to conduct basic studies to evaluate the functional aspect of cells regenerated by high frequency rMS. In addition, there is a study indicating that the expression of genes involved in cell recovery, such as cell repair and structural remodeling, increases after rTMS in a rat model of cerebral I/R injury (3). Based on this, further studies on cell recovery mechanism after rMS application may be helpful to understand the mechanism of rTMS.

As to the limitation of this study, our data are restricted to the effect of low- and high-frequency rMS over the same duration, which has been investigated in many previous studies. The different parameters such as the number of magnetic stimuli and duration cannot be disregarded (49-51). Therefore, further prospective studies to evaluate the effect of rMS based on the different durations for both low- and high-frequency rMS are needed.

In this study, we verified the neurobiological mechanism of rMS on I/R injury in neuronal cells, which depends on frequency. These results are valuable as a basic study for understanding the mechanism of rTMS treatment for stroke patients. This mechanism may be useful in developing more robust and reliable rTMS treatment protocols.

\section{REFERENCES}

1. Barker AT, Jalinous R, Freeston IL. Non-invasive magnetic stimulation of human motor cortex. Lancet (1985) 1:1106-7. doi:10.1016/S0140-6736 (85)92413-4

2. Hallett M. Transcranial magnetic stimulation and the human brain. Nature (2000) 406:147-50. doi:10.1038/35018000

3. Ljubisavljevic MR, Javid A, Oommen J, Parekh K, Nagelkerke N, Shehab S, et al. The effects of different repetitive transcranial magnetic stimulation (rTMS) protocols on cortical gene expression in a rat model of cerebral ischemicreperfusion injury. PLoS One (2015) 10:e0139892. doi:10.1371/journal.pone. 0139892

4. Fitzgerald PB, Daskalakis ZJ. The effects of repetitive transcranial magnetic stimulation in the treatment of depression. Expert Rev Med Devices (2011) 8:85-95. doi:10.1586/erd.10.57

5. Loo CK, Mcfarquhar TF, Mitchell PB. A review of the safety of repetitive transcranial magnetic stimulation as a clinical treatment for depression. Int J Neuropsychopharmacol (2008) 11:131-47. doi:10.1017/S1461145707007717

6. Lefaucheur JP, Andre-Obadia N, Antal A, Ayache SS, Baeken C, Benninger DH, et al. Evidence-based guidelines on the therapeutic use of repetitive transcranial magnetic stimulation (rTMS). Clin Neurophysiol (2014) 125:2150-206. doi:10.1016/j.clinph.2014.05.021

7. Pascual-Leone A, Valls-Sole J, Wassermann EM, Hallett M. Responses to rapid-rate transcranial magnetic stimulation of the human motor cortex. Brain (1994) 117(Pt 4):847-58. doi:10.1093/brain/117.4.847

8. Chen R, Classen J, Gerloff C, Celnik P, Wassermann EM, Hallett M, et al. Depression of motor cortex excitability by low-frequency transcranial magnetic stimulation. Neurology (1997) 48:1398-403. doi:10.1212/WNL.48.5.1398

9. Huang YZ, Edwards MJ, Rounis E, Bhatia KP, Rothwell JC. Theta burst stimulation of the human motor cortex. Neuron (2005) 45:201-6. doi:10.1016/j. neuron.2004.12.033

\section{CONCLUSION}

Following I/R injury, neuronal cell death can be induced in an in vitro neuronal model (Figure 7). When high-frequency rMS is treated in the in vitro neuronal model of $\mathrm{I} / \mathrm{R}$ injury, it can reduce neuronal cell death by increasing cell proliferation and antiapoptosis. Furthermore, it can also increase BDNF expression and synaptic plasticity by activating the $\mathrm{Ca}^{2+}$-CaMKII-CREB pathway. These results demonstrated the combined mechanism of high-frequency rMS in the in vitro neuronal model, and its mechanism could also be applied to other neurological diseases.

\section{AUTHOR CONTRIBUTIONS}

$\mathrm{AB}$ contributed to study conception and design, collection and/ or assembly of data, and manuscript writing. JHK contributed to manuscript writing and interpreted the data. SP contributed to manuscript writing and English editing. J-HJ and EJP contributed to collect and/or assembly of data. SHK and S-RC contributed to data analysis and interpretation, manuscript writing, and project supervision. All authors read and approved the manuscript.

\section{FUNDING}

This research was supported by grants from the National Research Foundation(2015M3A9B4067068, and2017R1D1A1B03028855); the Korea Health Technology R\&D Project through the Korea Health Industry Development Institute (KHIDI), funded by the Ministry of Health \& Welfare, Republic of Korea (HI16C1012); and from the "Dongwha" Faculty Research Assistance Program of Yonsei University College of Medicine (6-2016-0126).

10. Houdayer E, Degardin A, Cassim F, Bocquillon P, Derambure P, Devanne H. The effects of low- and high-frequency repetitive TMS on the input/output properties of the human corticospinal pathway. Exp Brain Res (2008) 187:207-17. doi:10.1007/s00221-008-1294-Z

11. Emara TH, Moustafa RR, Elnahas NM, Elganzoury AM, Abdo TA, Mohamed $\mathrm{SA}$, et al. Repetitive transcranial magnetic stimulation at $1 \mathrm{~Hz}$ and $5 \mathrm{~Hz}$ produces sustained improvement in motor function and disability after ischaemic stroke. Eur J Neurol (2010) 17:1203-9. doi:10.1111/j.1468-1331.2010.03000.x

12. Auriat AM, Neva JL, Peters S, Ferris JK, Boyd LA. A review of transcranial magnetic stimulation and multimodal neuroimaging to characterize post-stroke neuroplasticity. Front Neurol (2015) 6:226. doi:10.3389/fneur.2015.00226

13. Khedr EM, Ahmed MA, Fathy N, Rothwell JC. Therapeutic trial of repetitive transcranial magnetic stimulation after acute ischemic stroke. Neurology (2005) 65:466-8. doi:10.1212/01.wnl.0000173067.84247.36

14. Kim YH, You SH, Ko MH, Park JW, Lee KH, Jang SH, et al. Repetitive transcranial magnetic stimulation-induced corticomotor excitability and associated motor skill acquisition in chronic stroke. Stroke (2006) 37:1471-6. doi:10.1161/01.STR.0000221233.55497.51

15. Brodie SM, Meehan S, Borich MR, Boyd LA. $5 \mathrm{~Hz}$ repetitive transcranial magnetic stimulation over the ipsilesional sensory cortex enhances motor learning after stroke. Front Hum Neurosci (2014) 8:143. doi:10.3389/fnhum. 2014.00143

16. Takeuchi N, Chuma T, Matsuo Y, Watanabe I, Ikoma K. Repetitive transcranial magnetic stimulation of contralesional primary motor cortex improves hand function after stroke. Stroke (2005) 36:2681-6. doi:10.1161/01.STR. 0000189658.51972.34

17. Boggio PS, Alonso-Alonso M, Mansur CG, Rigonatti SP, Schlaug G, PascualLeone A, et al. Hand function improvement with low-frequency repetitive transcranial magnetic stimulation of the unaffected hemisphere in a severe case of stroke. Am J Phys Med Rehabil (2006) 85:927-30. doi:10.1097/01. phm.0000242635.88129.38 
18. Fregni F, Boggio PS, Valle AC, Rocha RR, Duarte J, Ferreira MJ, et al. A sham-controlled trial of a 5-day course of repetitive transcranial magnetic stimulation of the unaffected hemisphere in stroke patients. Stroke (2006) 37:2115-22. doi:10.1161/01.STR.0000231390.58967.6b

19. Meehan SK, Dao E, Linsdell MA, Boyd LA. Continuous theta burst stimulation over the contralesional sensory and motor cortex enhances motor learning post-stroke. Neurosci Lett (2011) 500:26-30. doi:10.1016/j. neulet.2011.05.237

20. Tretriluxana J, Kantak S, Tretriluxana S, Wu AD, Fisher BE. Low frequency repetitive transcranial magnetic stimulation to the non-lesioned hemisphere improves paretic arm reach-to-grasp performance after chronic stroke. Disabil Rehabil Assist Technol (2013) 8:121-4. doi:10.3109/17483107.2012. 737136

21. Dionisio A, Duarte IC, Patricio M, Castelo-Branco M. The use of repetitive transcranial magnetic stimulation for stroke rehabilitation: a systematic review. J Stroke Cerebrovasc Dis (2017) 27(1):1-31. doi:10.1016/j. jstrokecerebrovasdis.2017.09.008

22. Johansson BB. Brain plasticity and stroke rehabilitation. The Willis lecture. Stroke (2000) 31:223-30. doi:10.1161/01.STR.31.1.223

23. Ma J, Zhang Z, Su Y, Kang L, Geng D, Wang Y, et al. Magnetic stimulation modulates structural synaptic plasticity and regulates BDNF-TrkB signal pathway in cultured hippocampal neurons. Neurochem Int (2013) 62:84-91. doi:10.1016/j.neuint.2012.11.010

24. Lee JY, Park HJ, Kim JH, Cho BP, Cho SR, Kim SH. Effects of low- and high-frequency repetitive magnetic stimulation on neuronal cell proliferation and growth factor expression: a preliminary report. Neurosci Lett (2015) 604:167-72. doi:10.1016/j.neulet.2015.07.038

25. Luo J, Zheng H, Zhang L, Zhang Q, Li L, Pei Z, et al. High-frequency repetitive transcranial magnetic stimulation (rTMS) improves functional recovery by enhancing neurogenesis and activating BDNF/TrkB signaling in ischemic rats. Int J Mol Sci (2017) 18:E455. doi:10.3390/ijms18020455

26. Nour M, Scalzo F, Liebeskind DS. Ischemia-reperfusion injury in stroke. Interv Neurol (2013) 1:185-99. doi:10.1159/000353125

27. Abramov AY, Scorziello A, Duchen MR. Three distinct mechanisms generate oxygen free radicals in neurons and contribute to cell death during anoxia and reoxygenation. JNeurosci (2007) 27:1129-38. doi:10.1523/ JNEUROSCI.4468-06.2007

28. Gundimeda U, Mcneill TH, Elhiani AA, Schiffman JE, Hinton DR, Gopalakrishna R. Green tea polyphenols precondition against cell death induced by oxygen-glucose deprivation via stimulation of laminin receptor, generation of reactive oxygen species, and activation of protein kinase cepsilon. J Biol Chem (2012) 287:34694-708. doi:10.1074/jbc.M112.356899

29. Alluri H, Shaji CA, Davis ML, Tharakan B. Oxygen-glucose deprivation and reoxygenation as an in vitro ischemia-reperfusion injury model for studying blood-brain barrier dysfunction. J Vis Exp (2015) 99:e52699. doi:10.3791/ 52699

30. Zulueta JJ, Sawhney R, Yu FS, Cote CC, Hassoun PM. Intracellular generation of reactive oxygen species in endothelial cells exposed to anoxiareoxygenation. Am J Physiol (1997) 272:L897-902.

31. Zhu HY, Wang ZY, Xing YW, Gao YH, Ma T, Lou LX, et al. Baicalin reduces the permeability of the blood-brain barrier during hypoxia in vitro by increasing the expression of tight junction proteins in brain microvascular endothelial cells. J Ethnopharmacol (2012) 141:714-20. doi:10.1016/j. jep.2011.08.063

32. Livak KJ, Schmittgen TD. Analysis of relative gene expression data using realtime quantitative PCR and the 2(T)(-delta delta C) method. Methods (2001) 25:402-8. doi:10.1006/meth.2001.1262

33. Lonze BE, Ginty DD. Function and regulation of CREB family transcription factors in the nervous system. Neuron (2002) 35:605-23. doi:10.1016/ S0896-6273(02)00828-0

34. Adlung L, Kar S, Wagner MC, She B, Chakraborty S, Bao J, et al. Protein abundance of AKT and ERK pathway components governs cell typespecific regulation of proliferation. Mol Syst Biol (2017) 13:904. doi:10.15252/ msb. 20167258

35. Ashkenazi A, Dixit VM. Death receptors: signaling and modulation. Science (1998) 281:1305-8. doi:10.1126/science.281.5381.1305

36. Figurov A, Pozzo-Miller LD, Olafsson P, Wang T, Lu B. Regulation of synaptic responses to high-frequency stimulation and LTP by neurotrophins in the hippocampus. Nature (1996) 381:706-9. doi:10.1038/381706a0
37. Boss V, Roback JD, Young AN, Roback LJ, Weisenhorn DM, Medina-Flores R, et al. Nerve growth factor, but not epidermal growth factor, increases Fra-2 expression and alters Fra-2/JunD binding to AP-1 and CREB binding elements in pheochromocytoma (PC12) cells. J Neurosci (2001) 21:18-26.

38. Kimbrell TA, Little JT, Dunn RT, Frye MA, Greenberg BD, Wassermann EM, et al. Frequency dependence of antidepressant response to left prefrontal repetitive transcranial magnetic stimulation (rTMS) as a function of baseline cerebral glucose metabolism. Biol Psychiatry (1999) 46:1603-13. doi:10.1016/ S0006-3223(99)00195-X

39. Chervyakov AV, Chernyavsky AY, Sinitsyn DO, Piradov MA. Possible mechanisms underlying the therapeutic effects of transcranial magnetic stimulation. Front Hum Neurosci (2015) 9:303. doi:10.3389/fnhum.2015.00303

40. Speer AM, Kimbrell TA, Wassermann EM, D Repella J, Willis MW, Herscovitch P, et al. Opposite effects of high and low frequency rTMS on regional brain activity in depressed patients. Biol Psychiatry (2000) 48:1133-41. doi:10.1016/ S0006-3223(00)01065-9

41. Shaul U, Ben-Shachar D, Karry R, Klein E. Modulation of frequency and duration of repetitive magnetic stimulation affects catecholamine levels and tyrosine hydroxylase activity in human neuroblastoma cells: implication for the antidepressant effect of rTMS. Int J Neuropsychopharmacol (2003) 6:233-41. doi:10.1017/S1461145703003493

42. Vlachos A, Muller-Dahlhaus F, Rosskopp J, Lenz M, Ziemann U, Deller T. Repetitive magnetic stimulation induces functional and structural plasticity of excitatory postsynapses in mouse organotypic hippocampal slice cultures. J Neurosci (2012) 32:17514-23. doi:10.1523/ JNEUROSCI.0409-12.2012

43. Grehl S, Viola HM, Fuller-Carter PI, Carter KW, Dunlop SA, Hool LC, et al. Cellular and molecular changes to cortical neurons following low intensity repetitive magnetic stimulation at different frequencies. Brain Stimulat (2015) 8:114-23. doi:10.1016/j.brs.2014.09.012

44. Li J, Meng XM, Li RY, Zhang R, Zhang Z, Du YF. Effects of different frequencies of repetitive transcranial magnetic stimulation on the recovery of upper limb motor dysfunction in patients with subacute cerebral infarction. Neural Regen Res (2016) 11:1584-90. doi:10.4103/1673-5374.193236

45. Wang L, Zhang ZG, Zhang RL, Gregg SR, Hozeska-Solgot A, Letourneau Y, et al. Matrix metalloproteinase 2 (MMP2) and MMP9 secreted by erythropoietin-activated endothelial cells promote neural progenitor cell migration. J Neurosci (2006) 26:5996-6003. doi:10.1523/JNEUROSCI.5380-05.2006

46. Park H, Poo MM. Neurotrophin regulation of neural circuit development and function. Nat Rev Neurosci (2013) 14:7-23. doi:10.1038/nrn3379

47. Etcheverrigaray F, Bulteau S, Machon LO, Riche VP, Mauduit N, Leux C, et al. Treating depression with repetitive transcranial magnetic stimulation (rTMS): which repayment of a leading activity in psychiatry? Rev D Epidemiol Sante Pub (2017) 65:241-6. doi:10.1016/j.respe.2017.01.114

48. Blesneag AV, Slavoaca DF, Popa L, Stan AD, Jemna N, Isai Moldovan F, et al. Low-frequency rTMS in patients with subacute ischemic stroke: clinical evaluation of short and long-term outcomes and neurophysiological assessment of cortical excitability. J Med Life (2015) 8:378-87.

49. Pascual-Leone A, Houser CM, Reese K, Shotland LI, Grafman J, Sato S, et al. Safety of rapid-rate transcranial magnetic stimulation in normal volunteers. Electroencephalogr Clin Neurophysiol (1993) 89:120-30. doi:10.1016/ 0168-5597(93)90094-6

50. Wassermann EM, Grafman J, Berry C, Hollnagel C, Wild K, Clark K, et al. Use and safety of a new repetitive transcranial magnetic stimulator. Electroencephalogr Clin Neurophysiol (1996) 101:412-7. doi:10.1016/0924-980X(96)96004-X

51. Mishra BR, Sarkar S, Praharaj SK, Mehta VS, Diwedi S, Nizamie SH. Repetitive transcranial magnetic stimulation in psychiatry. Ann Indian Acad Neurol (2011) 14:245-50. doi:10.4103/0972-2327.91935

Conflict of Interest Statement: The authors declare that the research was conducted in the absence of any commercial or financial relationships that could be construed as a potential conflict of interest.

Copyright (C) 2018 Baek, Kim, Pyo, Jung, Park, Kim and Cho. This is an open-access article distributed under the terms of the Creative Commons Attribution License (CC BY). The use, distribution or reproduction in other forums is permitted, provided the original author(s) and the copyright owner are credited and that the original publication in this journal is cited, in accordance with accepted academic practice. No use, distribution or reproduction is permitted which does not comply with these terms. 